\title{
Factors influencing happiness in the elderly based on the Anderson
}

\section{model}

\section{Xueying Zhang", Shuang Huang", Lijia Jing, Zongzhuang Liu, Xin Wang, Li Li}

\author{
Xueying Zhang: Department of Health Management, School of Health Management, Harbin \\ Medical University, Harbin, China email: 2464987097@qq.com \\ Shuang Huang: Department of Health Management, School of Health Management, Harbin \\ Medical University, Harbin, China email: 804094493@qq.com \\ Lijia Jing: Department of Health Management, School of Health Management, Harbin Medical \\ University, Harbin, China email: 949262691@qq.com \\ Zongzhuang Liu: Department of Health Management, School of Health Management, Harbin \\ Medical University, Harbin, China email: 1195503970@qq.com \\ Xin Wang: Department of Health Management, School of Health Management, Harbin Medical \\ University, Harbin, China email: 562347568@qq.com \\ Li Li: Department of Health Management, School of Health Management, Harbin Medical \\ University, Harbin, China email: healthlaw@126.com \\ Correspondence: \\ Dr. Li Li, School of Public Health, Harbin Medical University, Baojian Road 157, Harbin, \\ China, Tel: 86-0451-87502879 Fax: 86-0451-87502885 E-mail: healthlaw@126.com \\ \#: These authors contributed equally to the work
}

\begin{abstract}
:
Background: The happiness of elderly people is an important indicator of successful aging. Research shows that happiness among the elderly is not only affected by physical conditions, social relations and other factors, but is also used as a measure of other aspects of happiness. This study examined the relationship between happiness and social relationships, contextual characteristics, and the medical outcomes of the elderly in China.

Methods: A total of 669 subjects over the age of 60 years were randomly selected from 13 cities in Heilongjiang province and surveyed using questionnaires. We used a structural equation based on the Anderson model to analyze the factors influencing happiness in the elderly.

Results: The main factors for happiness in the elderly were social relationships $(\mathrm{P}=0.51)$, contextual characteristics $(P=0.26)$, and medical outcomes $(P=0.23)$. Among these, the most important factor in the dimension of social relationships was social isolation $(\mathrm{P}=0.757)$, the most important factor in the dimension of contextual characteristics was monthly income $(\mathrm{P}=0.955)$, and the most important factor in the dimension of medical outcomes was physical health $(\mathrm{P}=0.600)$. There were also some relationships among three other dimensions.

Conclusions: For the elderly, we must pay attention to social relations and reduce the sense of social isolation. At the same time, we should provide more medical resources for the elderly and maintain their health.
\end{abstract}


Key words: elderly; happiness; Anderson model

\section{Background}

Happiness refers to an individual's subjective feelings about his or her lifestyle. It can be regarded as the subjective performance of individual welfare, including self-evaluations of health and life satisfaction ${ }^{12}$. With an aging population, happiness among the elderly is generally considered an important indicator of successful aging ${ }^{3}$. Research shows that elderly happiness is influenced by health, living conditions, social relations, and other factors ${ }^{4}$.

There are some differences in the factors affecting life happiness in different periods. According to an early theory of happiness, happiness comes directly from the objective environment of one's life. According to this theory, happiness pertains to personal income and consumption, which can increase the standard of living ${ }^{5}$. Therefore, many policy decisions are based on objective data. As research progressed, however, scholars have questioned this theory. Although objective environmental factors can reliably predict happiness, they only account for relatively small variances ${ }^{6}$. According to subsequent research, in addition to the objective environment, which has a direct impact on happiness, other factors affect happiness. Indeed, some studies explored the intermediary role between happiness and various variables.

There are many factors that influence individual happiness. Research on the elderly found that living with their children has a negative impact on the happiness of the elderly, whereas living with their grandchildren has a positive impact on their happiness ${ }^{7}$. Personal economic status is another factor affecting happiness, and economic pressure increases the probability of unhappiness by 4.3 times. When the national economic situation is poor, unhappiness among the elderly increases. That is, elderly happiness increases with improvements to the economic situation. For the elderly, economic conditions can achieve a higher standard of living, and medical services are a means to achieving happiness ${ }^{8}$. A survey of the elderly in Canada by Wister found that there is a positive relationship between happiness and participation in social activities ${ }^{9}$.

Happiness is also affected by other factors. Di Tella used the Eurobarometer, which collects data on life satisfaction, to study the relationship between unemployment, inflation, and happiness ${ }^{10}$. Happiness can also be used to measure external economic indicators. For example, Nordhaus and Krueger used happiness to evaluate changes in the consumer price index and household income ${ }^{1112}$. After discovering the potential value of happiness, the company surveyed their employees' satisfaction and happiness ${ }^{13}$.

Currently, research on happiness tends to focus on the elderly, teenagers, and other specific groups. Structural equations, multiple regression, and other statistical methods are often used to study the factors influencing happiness. However, there is a lack of overall consideration of the factors affecting individual happiness. Happiness pertains to an individual's comprehensive judgment of his or her life state, which reflects self-perceptions of health ${ }^{14}$. Thus, the Anderson model includes many factors that can affect health in a relatively mature framework for discussion. Our study is based on this model. A structural equation model was used to measure the relationship between happiness and several variables, measuring both dominant and recessive variables. Based on the Anderson model, we included variables regarding social relationships, as this is more in line with the actual situation faced by the elderly in China. Life satisfaction and the positive influence of happiness are the most commonly used indicators of experiential well-being ${ }^{15}$. In many international surveys, life satisfaction is used as a representative of happiness. Therefore, this paper uses life satisfaction indicators to 
measure the happiness of the elderly ${ }^{1617}$.

\section{Methods}

\section{Data and sample}

We divided Heilongjiang into three economic levels, and one city was selected at each level: Harbin, Qiqihar, and Jiamus. Similarly, according to the economic level, three communities and three villages were selected from each city, for a total of nine communities and nine villages. Individuals were included in the study if they met the following criteria: aged 60 years or older, with clear consciousness, and competence at verbal communication.

\section{Data collection}

A field questionnaire survey was conducted from March 1, 2016 to August 31, 2016. The investigators were postgraduates and undergraduates who received unified training. Data were collected through face-to-face interviews using a structured questionnaire. At the early stage of the survey, the questionnaire was standardized by issuing an operation manual to ensure that the questions asked by the investigators were consistent. A preliminary survey was first carried out. Then, the questionnaire was modified and the investigators were re-trained. In total, 1200 questionnaires were distributed (600 urban and 600 rural). Participants who did not respond to the survey or did not answer questions about willingness to receive eldercare were excluded. Ultimately, a total of 1003 valid questionnaires (581 from urban elderly, and 422 from rural elderly) were obtained, with an effective response rate of $83.6 \%$.

\section{Assessment tools}

Based on the health behavior model proposed by Anderson, we analyzed the factors influencing elderly happiness. A questionnaire with five sections was used.

The first section focused on the demographics of the respondents, including gender, age, marital status, medical insurance, real estate, and monthly income.

The second section investigated happiness. The five-item version of Pavot and Diener's lifesatisfaction scale was used for the measurement. Respondents were asked to indicate their level of agreement with the respective statements from a score of 1 (strongly disagree) to 7 (strongly agree). Then, the scores of each item were averaged. The reliability of the scale was reasonable in our sample, and the Cronbach's $\alpha$ was 0.96 .

The third section was mainly about social relations, with questions regarding social isolation, satisfaction with interpersonal relationships, and satisfaction with the support received by friends. The social isolation scale mainly adopted that proposed by Hawthorne. There were six questions in the scale, among which the second, fifth, and sixth questions needed to be scored reversely. A Likert fivepoint scale was adopted: a higher score indicated a stronger sense of social isolation. The Cronbach's $\alpha$ was 0.83 , which indicates high specificity. Satisfaction with interpersonal relationships and support from friends was respectively determined with two questions: Are you satisfied with your interpersonal relationships? And are you satisfied with the support you receive from your friends? Respondents were asked to use a five-point scale to indicate their satisfaction, ranging from 1 (not satisfied at all) to 5 (very satisfied).

The fourth section investigated the quality of life of the elderly, mainly using an EQ-5D scale. The EQ-5D scale was developed by the British EuroQol Group to provide a simple and universal method of measuring health for clinical and economic evaluations. It contains five dimensions: mobility, selfcare, usual activities, pain/discomfort, and anxiety/depression. 
The fifth section mainly evaluated medical treatment of the elderly. Specifically, the participants were asked whether they had been hospitalized in the last year. They were also asked whether they have had chronic diseases in the last year. In both cases, if they had, the answers were scored with 1 point, and otherwise they were scored with 0 .

\section{Data analysis}

Data were processed using Epidata and were double-entered to ensure quality. Sample characteristics were analyzed using SPSS V.19.0. Descriptive statistics were reported for socioeconomic and demographic characteristics, physical health, and life satisfaction in urban and rural areas. According to the actual situation of the elderly in China, we used social relations to replace healthy behavior in Anderson's model. In addition, demographic variables could not be included in the structural equation as explicit variables, so the path of individual characteristics was excluded. Finally, the structural equation model was used to measure the relationship among contextual characteristics, social relationships, medical outcomes, and happiness. The following indices were used to evaluate the overall model fit: the goodness-of-fit statistic, the goodness-of-fit index (GFI), the Tucker-Lewis index (TLI), the comparative fit index (CFI), and the root mean square error of approximation (RMSEA).

\section{Results}

\section{Demographic characteristics}

Table 1 shows the socioeconomic and demographic characteristics of the participants. In the sample, $47.3 \%$ respondents were male, and $52.7 \%$ were female. The age of the elderly was mainly concentrated between 60 and 70 years old (50.6\%), 27.9\% were between 70 and 79 years old, and $21.4 \%$ were older than 80 years old. Most respondents had children (94.7\%). The proportion of the elderly who owed property was $61.3 \%$. In addition, the monthly income of the elderly was such that $35.3 \%$ had less than 999 RMB, 19.8\% had between 1000 RMB and 1999 RMB, 27.7\% had between 2000 RMB and 2999 RMB, and $17.1 \%$ had more than 3000 RMB.

\section{Structural equation modelling}

The Andersen model showed that each coupled dimension was related. We connected every two exogenous variables to build a structural equation model for happiness (Figure 1). The regression weights and standardized regression weights are shown in Table 2. As can be seen from Table 2, the path of satisfaction with community medical institutions was not statistically significant $(p=0.193$, $>0.05$ ), and so the path was eliminated. In light of this, we rebuilt the model after correcting it (Figure 2). The regression weights and standardized regression weights of this model are shown in Table 3, showing that every path is meaningful. The goodness-of-fit index of the model was suitable for the requirements of the structural model (Table 4).

The path coefficient from social relationships to happiness was 0.507 , which is statistically significant at $p<0.001$. Social relationships thus had a positive effect on elderly happiness. The relationship between contextual characteristics and happiness was 0.256 , which is statistically significant at $p<0.001$. Thus, contextual characteristics had a positive effect on elderly happiness. The relationship between medical outcomes and happiness was 0.232 , which is statistically significant at $p$ $<0.001$. Thus, medical outcomes had a positive effect on elderly happiness.

\section{Discussion}

The Anderson model provides a mature framework in which social relationships, contextual 
characteristics, and medical outcomes were included to observe their impact on elderly happiness. In recent years, the happiness of Chinese people has significantly improved ${ }^{18}$. The results of this study show that social relations, environmental factors, and medical outcomes have the greatest impact on the happiness of the elderly.

First, Table 3 shows that social relationships are the most influential factors for the happiness of the elderly. This is consistent with the results of Moeini ${ }^{1920}$. A good social support network can increase quality of life ${ }^{21}$, thus improving happiness. Xiaotong proposed the difference model to explain the composition of China's social network. Compared to Western society, relatives account for a higher proportion of Chinese social networks ${ }^{22}$. Research has shown that satisfaction with interpersonal relationships and support from friends importantly impact happiness. Due to family and work, adult children rarely have time to accompany their parents ${ }^{23}$, so the role of the community with regard to the happiness of the elderly should be emphasized. In developed countries, social isolation is a problem that needs attention. The elderly are vulnerable to a loss in social relationships, since community resources to form social networks in old age are limited ${ }^{24}$. Reducing social isolation of the elderly and promoting their integration into society is an urgent problem.

Second, contextual characteristics played the second-biggest role in the happiness of the elderly, according to our study. In this dimension, the main influential factor was monthly income, which is consistent with the results of Shamsk and other studies ${ }^{2526}$. According to the Easterlin paradox, personal income is closely related to happiness. The theory states that at the micro-level, personal income is positively correlated with happiness. At the macro-level, however, there is no significant correlation between a country's economic growth and national happiness. Although Junqiang questioned the applicability of this theory to China, Easterlin's subsequent survey of developing countries showed that economic growth and national happiness have a U-shaped trend. This theory has been confirmed in a study specifically aimed at China. Since 1990, China's resident happiness index has been on a downward trend, dropping to its lowest level between the years 2000 and 2005, and then slowly picking up. Therefore, the revised Easterlin paradox still applies to China. For the elderly, there is a positive correlation between personal income and happiness. In 2016, no city in Heilongjiang was among the top ten cities in China's urban happiness index. According to the official website of China's National Bureau of Statistics, in 2016, Heilongjiang ranked 18th in terms of per capita disposable income. Therefore, we should pay more attention to the income of the elderly to improve their happiness.

Finally, there is a correlation between medical outcomes and the happiness of the elderly, and there is a positive correlation between self-assessment of health and happiness, which is consistent with the results of other research ${ }^{2728}$. Indeed, the deterioration of health will lead to a decline in happiness ${ }^{29}$. According to our survey, elderly who were not hospitalized or ill were happier. This is consistent with the results of a survey ${ }^{30}$. A decline in health as a result of stroke or cancer, for example, negatively affects happiness ${ }^{31}$. The relationship between disease and happiness is complex, and disease can affect happiness through its impact on health. The extent of disease has various effects on the ability of the elderly to care for themselves, which, in turn, affects their overall level of happiness ${ }^{32}$. According to hedonic adaptation theory, however, people adapt to disease over time, and the effect of physical health on happiness gradually decreases ${ }^{33}$. In addition, mental health must be considered. Better screening, diagnosis, and treatment for depression, social phobia, and other mental disorders that afflict the elderly cannot be ignored.

The influence of contextual characteristics, social relationships, and medical outcomes on the 
happiness of the elderly is not independent. Retired elderly, especially those in poor health, spend most of their time in the community ${ }^{34}$. Due to the physical health and family life of the elderly, social networks in later years are shrinking. Therefore, interpersonal communication in the community and elderly satisfaction with the acquisition of medical resources are important. They help the elderly to maintain their health and reduce their loneliness.

\section{Conclusions}

Increasing attention has been paid to the happiness of the elderly. Regarding this, we should attach importance to social communication networks for the elderly. Good social communication can reduce the sense of social isolation. In addition, sufficient medical resources should be provided for the elderly to ensure their health and improve their well-being.

\section{Declarations}

Ethics approval and consent to participate

Approval for this study was granted by the Institutional Research Board of Harbin Medical University. The data were collected anonymously. Respondents were assured that participation in this survey was voluntary, with the return of completed questionnaires taken as consent to participate.

\section{Consent for publication}

All presentations of case reports received consent for publication.

Availability of data and materials

Data will not be shared. We promised not disclose information regarding the respondents when we signed the informed consent form.

\section{Competing interests}

The authors declare that they have no competing interests.

\section{Funding}

This study was funded by the National Science Foundation of China (NSFC), No. 71573066/G0308.

\section{Author contributions}

LL conceived and designed the experiments. XW performed the experiments. LJ analyzed the data. ZL, LJ, and LL contributed reagents/materials/analysis tools. XZ and SH wrote the paper. XS and XW provided technical support. LL critically revised the paper. All authors checked and proofread the final version of the manuscript.

\section{Acknowledgements}

The authors would like to thank all of the participants in this study. Furthermore, we are grateful to $\mathrm{Dr}$. Li Li for her guidance on the writing of the manuscript, and we thank International Science Editing (http://www.internationalscienceediting.com) for editing the manuscript. 
Figure 1

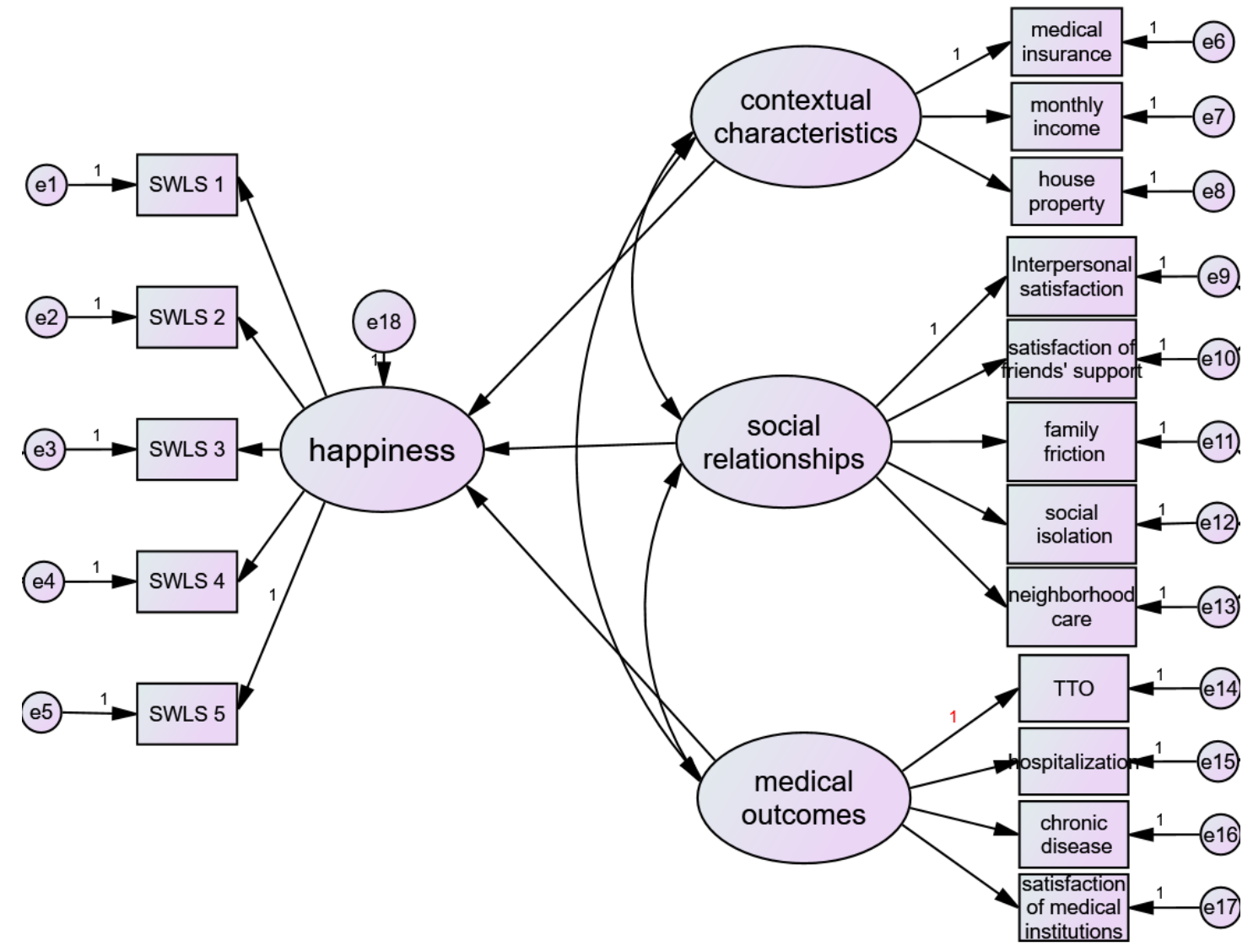

Figure 2

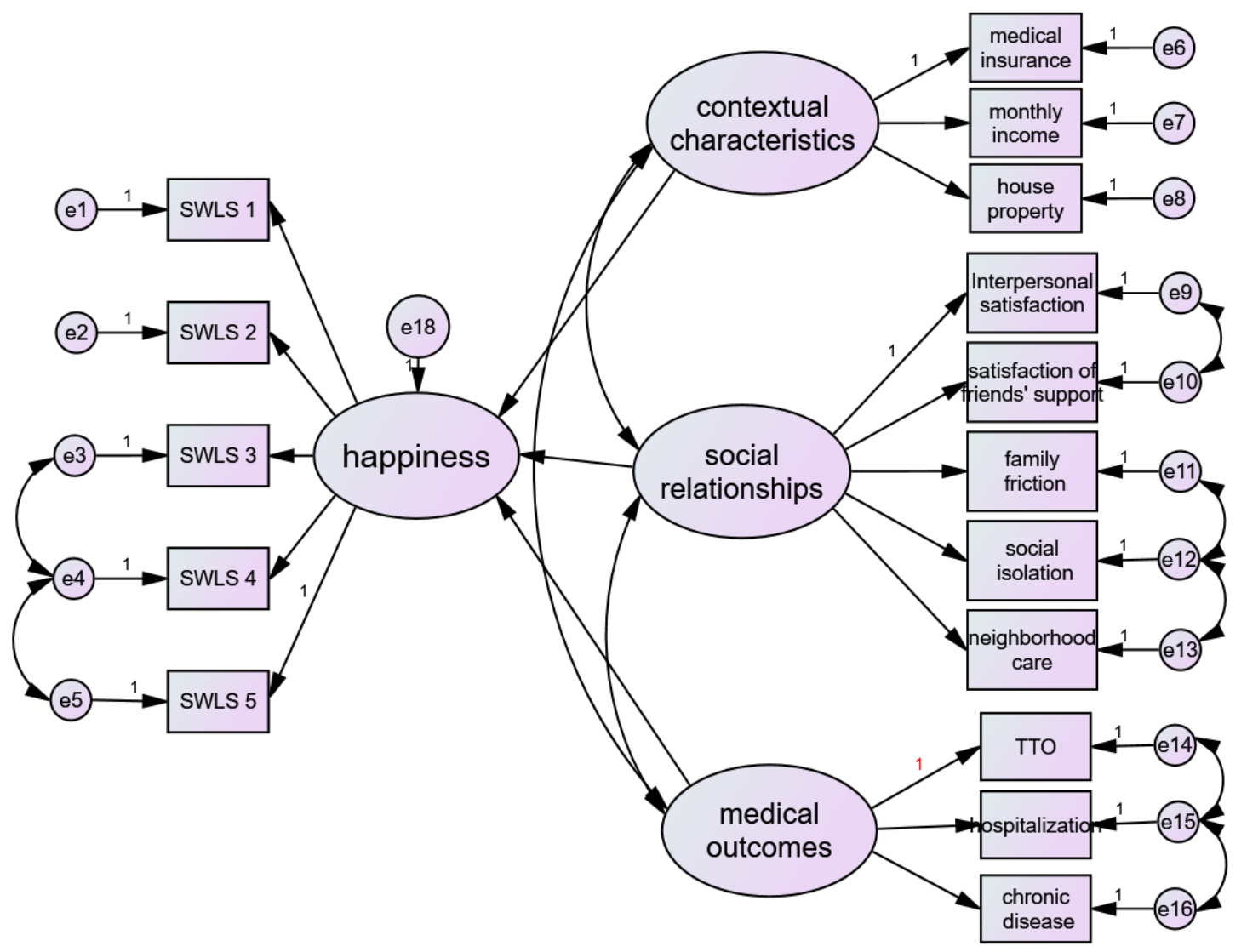


Table 1. Socioeconomic and demographic characteristics of the elderly.

\begin{tabular}{|c|c|c|}
\hline Variables & $\begin{array}{l}\text { Total } \\
1003 \\
\mathrm{~N} \\
\end{array}$ & $\%$ \\
\hline \multicolumn{3}{|l|}{ sex } \\
\hline male & 474 & 47.3 \\
\hline female & 529 & 52.7 \\
\hline \multicolumn{3}{|l|}{ age } \\
\hline$<70$ & 508 & 50.6 \\
\hline $70-79$ & 280 & 27.9 \\
\hline$>=80$ & 215 & 21.4 \\
\hline \multicolumn{3}{|l|}{ marriage status } \\
\hline having partner & 410 & 40.9 \\
\hline without partner & 593 & 59.1 \\
\hline \multicolumn{3}{|l|}{ have children } \\
\hline yes & 950 & 94.7 \\
\hline no & 53 & 5.3 \\
\hline \multicolumn{3}{|l|}{ house property } \\
\hline yes & 615 & 61.3 \\
\hline no & 388 & 38.7 \\
\hline \multicolumn{3}{|l|}{ monthly income } \\
\hline$<=999$ & 354 & 35.3 \\
\hline 1000-1999 & 199 & 19.8 \\
\hline 2000-2999 & 278 & 27.7 \\
\hline$>=3000$ & 172 & 17.1 \\
\hline
\end{tabular}

Table 2. Regression weights and standardized regression weights

\begin{tabular}{lrrr}
\hline \multicolumn{1}{c}{ Variables } & $\begin{array}{r}\text { Unstandardize } \\
\text { d direct effects }\end{array}$ & $\begin{array}{r}\text { Standardized } \\
\text { direct effects }\end{array}$ & P \\
\hline happiness $<-$--contextual characteristics & 4.536 & .262 & $* * *$ \\
happiness $<-$--social relationships & .855 & .470 & $* * *$ \\
happiness $<-$--medical outcomes & 2.239 & .235 & $* * *$ \\
SWLS 4 <---happiness & 1.153 & .921 & $* * *$ \\
SWLS 3 <---happiness & 1.220 & .966 & $* * *$ \\
SWLS 2 <---happiness & 1.260 & .978 & $* * *$ \\
medical insurance $<---$ contextual characteristics & 1.000 & .215 & \\
monthly income $<---$ contextual characteristics & 21694.106 & .954 & .001 \\
house property $<---$ contextual characteristics & 1.258 & .158 & $* * *$ \\
\hline
\end{tabular}




\begin{tabular}{|c|c|c|c|}
\hline satisfaction of friends' support<---social relationships & 1.048 & .828 & $* * *$ \\
\hline family friction<---social relationships & -.424 & -.315 & $* * *$ \\
\hline social isolation<---social relationships & -5.675 & -.714 & $* * *$ \\
\hline TTO<---medical outcomes & 1.000 & .641 & \\
\hline hospitalization <---medical outcomes & -1.458 & -.333 & $* * *$ \\
\hline chronic disease $<---$ medical outcomes & -1.474 & -.377 & $* * *$ \\
\hline $\begin{array}{l}\text { satisfaction of medical institutions }<--- \text { medical } \\
\text { outcomes }\end{array}$ & -.920 & -.053 & .193 \\
\hline SWLS 1<---happiness & 1.229 & .938 & $* * *$ \\
\hline SWLS 5<---happiness & 1.000 & .759 & \\
\hline Interpersonal satisfaction <---social relationships & 1.000 & .817 & \\
\hline neighborhood care<---social relationships & 1.037 & .513 & $* * *$ \\
\hline
\end{tabular}

Table 3. Regression weights and standardized regression weights

\begin{tabular}{|c|c|c|c|}
\hline Variables & $\begin{array}{l}\text { Unstandardized } \\
\text { direct effects }\end{array}$ & $\begin{array}{l}\text { Standardized } \\
\text { direct effects }\end{array}$ & $\mathrm{P}$ \\
\hline happiness $<---$ contextual characteristics & 4.363 & .256 & $* * *$ \\
\hline happiness $<---$ social relationships & 1.029 & .507 & $* * *$ \\
\hline happiness<---medical outcomes & 2.320 & .232 & .015 \\
\hline SWLS $4<---$ happiness & 1.155 & 909 & $* * *$ \\
\hline SWLS $3<---h a p p i n e s s$ & 1.232 & .959 & $* * *$ \\
\hline SWLS $2<---$ happiness & 1.289 & .985 & $* * *$ \\
\hline medical insurance $<---$ contextual characteristics & 1.000 & .215 & \\
\hline monthly income <---contextual characteristics & 21767.406 & .955 & .002 \\
\hline house property <---contextual characteristics & 1.260 & .158 & $* * *$ \\
\hline satisfaction of friends' support<---social relationships & 1.047 & .729 & $* * *$ \\
\hline family friction $<---$-social relationships & -.473 & -.310 & $* * *$ \\
\hline social isolation $<---$ social relationships & -6.806 & -.757 & $* * *$ \\
\hline TTO $<---$ medical outcomes & 1.000 & .600 & \\
\hline hospitalization<----medical outcomes & -1.000 & -.214 & $* * *$ \\
\hline chronic disease $<---$ medical outcomes & -1.451 & -.347 & $* * *$ \\
\hline SWLS 1<---happiness & 1.252 & .939 & $* * *$ \\
\hline SWLS 5<---happiness & 1.000 & .747 & \\
\hline Interpersonal satisfaction <---social relationships & 1.000 & .721 & \\
\hline neighborhood care <---social relationships & 1.170 & .510 & $* * *$ \\
\hline
\end{tabular}

Table 4. The model estimates the fitting index value

\begin{tabular}{llll}
\hline GFI & TLI & CFI & RMSEA \\
\hline 0.963 & 0.970 & 0.977 & 0.046 \\
\hline
\end{tabular}

1. Luchesi B M , De Oliveira N A, De Morais D, et al. Factors associated with happiness in the elderly 
persons living in the community. Archives of Gerontology and Geriatrics. 2018;74:83-87.

2. Higgins E, Grant H, Shah J, et al. Well-Being: The Foundation of Hedonic Psychology. New York, Russell Sage Foundation.1999.

3. Cramm J M , Van D H M , Nieboer A P. The Importance of Neighborhood Social Cohesion and Social Capital for the Well Being of Older Adults in the Community. The Gerontologist(1):1.

4. Sprangers M A G , Regt E B D , Andries F, et al. Which chronic conditions are associated with better or poorer quality of life? Journal of Clinical Epidemiology.2000; 53(9):895-907.

5. Campbell A, Converse P E , Rodgers W L. The Quality of American Life: Perceptions, Evaluations, and Satisfactions. Academy of Management Review.1976;2(4):694.

6. Diener E, Suh E M, Lucas R E, et al. Subjective Well-Being: Three Decades of Progress. Psychological Bulletin, 1999;125(2):276-302.

7. Chyi H , Mao S. The Determinants of Happiness of China's Elderly Population. Journal of Happiness Studies, 2012; 13(1):167-185.

8. Demographic and socioeconomic inequalities for self-rated health and happiness in elderly: The situation for Turkey regarding World Values Survey between 1990 and 2013. Archives of Gerontology and Geriatrics. 61(2): 224-230.

9. Theurer K, Wister A . Altruistic behaviour and social capital as predictors of well-being among older Canadians. Ageing and Society. 2010;30(01):157-181.

10. Di Tella R, Macculloch R J, Oswald A J . Preferences over Inflation and Unemployment: Evidence from Surveys of Happiness. American Economic Review. 2001; 91(1):335-341.

11. Nordhaus, William D . Quality Change in Price Indexes. Journal of Economic Perspectives. 1998; 12(1):59-68.

12. Krueger A B , Siskind A. Using survey data to assess bias in the Consumer Price Index. Monthly labor review / U.S. Department of Labor, Bureau of Labor Statistics. 1998; 121(4):24-31.

13. Krueger K A B . Developments in the Measurement of Subjective Well-Being. The Journal of Economic Perspectives. 2006; 20(1):3-24.

14. Veenhoven R. Conditions of happiness. 1984.

15. Busseri, Michael A. Toward a Resolution of the Tripartite Structure of Subjective Well-Being. Journal of Personality. 2015; 83(4):413-428.

16. Angus, Deaton. Income, Health, and Well-Being around the World: Evidence from the Gallup World Poll. The Journal of Economic Perspectives. 2008.

17. Helliwell, J. F., Layard, R., \& Sachs, J. (Eds.). (2018). World happiness report 2018. New York, NY: Sustainable Development Solutions Network.

18. Clark W A V, Yi D, Huang Y. Subjective well-being in China's changing society. Proceedings of the National Academy of Sciences. 2019; 116(34): 16799-16804.

19. Moeini B , Barati M , Farhadian M , et al. The Association between Social Support and Happiness among Elderly in Iran. Korean Journal of Family Medicine. 2018.

20. Wang $X$. Subjective well-being associated with size of social network and social support of elderly. Journal of Health Psychology. 2014; 21(6):1037-1042.

21. Symister $P$. Beyond social support: Using family expectations to predict psychological adjustment in endstage renal disease patients. Journal of Health Psychology. 2011; 16(7):1015-1026.

22. Silverman P, Hecht L , Mcmillin J D. Modeling life satisfaction among the aged: a comparison of Chinese and Americans. Journal of cross-cultural gerontology. 2000.

23. Yip N M , Leung T T F , Huang R . Impact of Community on Personal Well-Being in Urban China. Journal of Social Service Research. 2013; 39(5):675-689.

24. Saito T, Kai I, Takizawa A. Effects of a program to prevent social isolation on loneliness, depression, and subjective well-being of older adults: a randomized trial among older migrants in Japan. Archives of 
gerontology and geriatrics. 2012; 55(3): 539-547.

25. Shams K. Determinants of Subjective Well-Being and Poverty in Rural Pakistan: A Micro-Level Study. Social Indicators Research. 2014; 119(3).

26. German L, Carmen L M D , Berta S. In the choice between health and money, health comes first: an analysis of happiness among rural Chilean elderly. Cadernos de Saúde Pública. 2016; 32(5).

27. chneider G, Driesch G, Kruse A, et al. What influences self-perception of health in the elderly? The role of objective health condition, subjective well-being and sense of coherence. Archives of gerontology and geriatrics. 2004; 39(3): 227-237.

28. Ní Mhaoláin, Aine M, Gallagher D , O Connell H, et al. Subjective well-being amongst communitydwelling elders: what determines satisfaction with life? Findings from the Dublin Healthy Aging Study. International Psychogeriatrics. 2012; 24(02):316-323.

29. Diener E, Pressman S D, Hunter J, et al. If, Why, and When Subjective Well-Being Influences Health, and Future Needed Research. Applied Psychology Health and Well-Being. 2017; 9(2):133-167.

30. Ergin I, Mandiracioglu A. Demographic and socioeconomic inequalities for self-rated health and happiness in elderly: The situation for Turkey regarding World Values Survey between 1990 and 2013. Archives of Gerontology and Geriatrics. 2015; 61(2):224-230.

31. Binder M , Coad A . Life satisfaction and self-employment: a matching approach. Small Business Economics. 2013; 40(4):1009-1033.

32. Angner, E., Ghandhi, J., Williams Purvis, K., Amante, D., \& Allison, J. (2013). Daily functioning, health status, and happiness in older adults. Journal of Happiness Studies. 14(5):1563-1574.

33. Lucas, Richard E . Adaptation and the Set-Point Model of Subjective Well-Being: Does Happiness Change After Major Life Events?. Current Directions in Psychological Science. 2007; 16(2):75-79.

34. Liddle J , Scharf T, Bartlam B , et al. Exploring the age-friendliness of purpose-built retirement communities: evidence from England. Ageing and Society. 2014; 34(09):1601-1629. 